\title{
OS ALUNOS DE ADMINISTRAÇÃO ESTÃO EM SINTONIA COM O MERCADO DE TRABALHO?
}

\author{
Fábio Mosso Moreira*; Timóteo Ramos Queiroz**; \\ Nayele Macini***; Gabriela Hermida Campeão****
}

Recebido: 08 fev. 2012 Aprovado: 20 abr. 2012

\author{
* Universidade Estadual Paulista “Julio de Mesquita Filho”. Tupã, SP, Brasil. Contato: fabiomoreira@tupa. \\ unesp.br \\ ** Universidade Estadual Paulista "Julio de Mesquita Filho”. Tupã, SP, Brasil. Contato: timoteo@tupa. \\ unesp.br. \\ *** Universidade Estadual Paulista "Julio de Mesquita Filho". Tupã, SP, Brasil. Contato: nmacini@yahoo. \\ com.br. \\ ***** Universidade Estadual Paulista "Julio de Mesquita Filho". Tupã, SP, Brasil. Contato: gabe.camp@ \\ hotmail.com.
}

Resumo: O presente artigo realiza o levantamento de demandas em relação ao perfil dos profissionais de Administração pelo mercado de trabalho, descreve tais características e analisa como os alunos do curso de Administração da UNESP/Tupã se encontram em relação a tais quesitos. Os pontos levantados demonstram interesses do mercado de trabalho não somente para conhecimentos de formação técnica-acadêmica, como também, conhecimentos e habilidades interpessoais e extracurriculares. Estes pontos foram identificados através de um estudo bibliográfico e da consulta a formulários de vagas de estágio e emprego do projeto de extensão Balcão de Estágios e Empregos, na UNESP/ Tupã. A partir da comparação entre estas fontes, foi possível identificar as principais competências procuradas pelas empresas no perfil de um administrador. Com caracterização do objeto de estudo foi possível realizar comparações em relação ao termo em que o aluno se encontrava no curso $\left(3^{\circ}, 5^{\circ}\right.$ e $7^{\circ}$ semestres), tanto como em relação ao período (diurno e noturno), verificando se tais competências evoluíam com o passar do curso. O trabalho conclui também que não basta para os alunos de administração restringir sua formação apenas com os conhecimentos acadêmicos, sendo necessário para a formação de um perfil adequado, o desenvolvimento de atividades extracurriculares que incrementem competências como conhecimento de informática e idiomas. Constatações relevantes demonstraram que a formação dos alunos, e a forma como reagem às demandas, estão fortemente conectadas às exigências de mercado.

Palavras-chave: Avaliação. UNESP. Curso de Administração. Discentes. Demandas de mercado.

\section{ARE ADMINISTRATION STUDENTS IN TUNE WITH THE JOB MARKET?}

ABSTRACT : This article provides a survey of the demands placed by the labor market in relation to the profile of business administration professionals. It describes the characteristics of such profile and analyzes how UNESP/Tupa's administration students fare in relation to such questions. The points raised show that the labor market is interested not only in technical-academic knowledge but also in knowledge and interpersonal and extracurricular skills. These points were identified through studies of the pertinent literature study and based on consultation of apprenticeship and employment forms of UNESP/Tupa's job extension project for Internships and Jobs. The comparison between these sources made it possible to identify the main skills sought by companies when searching for an administrator. With the characterization of the object of study it was possible to compare the stage level in which the student was placed (3rd , 5th and 7th semesters), in regard to both day and night shifts, verifying whether these skills evolved with the student's trajectory through the program. The study also concludes that it is not enough for administration students to restrict their training to academic knowledge. An appropriate profile demands the development of extracurricular activities that enhance competencies such as computer skills and languages. Relevant findings demonstrated that the education of students and how they react to demands are strongly connected to market demands.

Keywords : Evaluation. UNESP. Business administration programs. Students. Market Demands 


\section{INTRODUÇÃO}

As organizações no contexto atual estão passando por um intenso processo de transformação no modo de gerir pessoas, e o mercado cada vez mais exige das organizações um perfil flexível e maior velocidade de resposta na resolução de problemas e busca de resultados.

Segundo os autores Silva, Santana e Pereira Neto (2010), a crise americana de 2008 que afetou a produção industrial e o mercado financeiro de capitais causou mudanças nos cenários internacionais e afetou a economia da maioria dos países, principalmente Europeus. Essas mudanças refletiram na necessidade de adaptação das empresas frente à nova dinâmica mundial exigindo maior flexibilidade e velocidade de respostas das organizações, que passaram a exigir mais dos trabalhadores, buscando profissionais flexíveis, multiqualificados e multifuncionais para atender as necessidades de um novo mercado mais competitivo.

Para que tal competitividade seja alcançada, os mesmos autores afirmam que o mercado atual requer o perfil de um administrador com uma visão generalista de conhecimentos em diversas áreas administrativas, como contabilidade, economia, direito, gestão ambiental entre outros, geralmente obtidos na graduação. Porém, alertam que o administrador moderno deve sempre buscar o aprimoramento de suas competências com atividades diversas, gerando assim um processo complexo de formação de um perfil considerado adequado.

Neste ambiente de nova dinâmica mundial e de necessidade do aumento da competitividade pelas empresas, Lemos, Dubeux e Pinto (2009) tratam da valorização da formação profissional como estratégia de enfretamento do desemprego, onde os países da União Européia tratam com maior ênfase do que no Brasil. Neste contexto, o papel da educação é visto não mais como promotor do desenvolvimento econômico, mas como oportunidade de aumentar as chances individuais na inserção do mercado de trabalho.

O ensino de Administração no Brasil é considerado o de maior demanda de alunos para o Ensino Superior. Segundo o Censo da Educação Superior realizado anualmente pelo Instituto Nacional de Estudos e Pesquisas Educacionais (INEP, 2009), onde as Instituições de Ensino Superior (IES) respondem um questionário sobre sua estrutura e cursos, o curso de Administração em 2009 contava com mais de um milhão de matrículas (1.102.579) e $18,5 \%$ dos estudantes do ensino superior. Com tantos cursos de Administração no país, muitos destes administradores, após saírem da 
graduação, se deparam com o mercado sem a formação adequada para suprir as demandas do mesmo.

Añez et al. (2007) afirmam que as deficiências no perfil do profissional em Administração tem sido foco de várias pesquisas e estudos no Brasil e no mundo, e cita a formação acadêmica como um dos fatores, pois encontra-se distante das expectativas de trabalho. Para os autores, o ensino da Administração necessita de ferramentas e metodologias didáticas que exponham mais os alunos ao exercício do pensamento sistêmico, para assim melhor compreender os problemas organizacionais em ambientes cada vez mais complexos.

Dentre as universidades que ofertam cursos de Administração está a Universidade Estadual Paulista "Júlio de Mesquita Filho" (UNESP), tendo entre suas 33 unidades o Campus Experimental de Tupã (CET), criado juntamente com o Curso de Administração. Tal unidade está localizada na cidade de Tupã, região da Nova Alta Paulista. A formação desta unidade, relativamente recente, começa com o ofício $n^{\circ}$ 512/02 aprovado em Agosto de 2002 pelo Conselho Universitário da UNESP, que promovia uma nova expansão com a abertura de oito novas unidades e criação de novos cursos em campi já existentes (UNESP/Tupã, 2011). Foi inaugurada em 2003 e conta atualmente com a graduação em Administração, além do curso semipresencial de Pedagogia e da pós-graduação em Gestão do Agronegócio. Segundo Lourenzani (2007) a UNESP/Tupã com apenas três anos de criação conquistou o $3^{\circ}$ lugar no ranking dos cursos de Administração do estado de São Paulo e $14^{\circ}$ lugar no ranking nacional, baseado no Exame Nacional de Desempenho dos Estudantes (ENADE, 2006). Em 2009 foi reconhecida como o Campus mais produtivo entre os Campi Experimentais da UNESP, com relação à pesquisa e captação de recursos (UNIVERSIA, 2010).

Neste contexto, este trabalho tem como objetivo verificar se o perfil de futuros profissionais do curso de Administração da UNESP/Tupã está condizente com o perfil de profissionais que o mercado demanda. Primeiramente, a pesquisa procura identificar os principais fatores que o mercado atual exige das empresas, e consequentemente as competências que esta exige como pré-requisitos no recrutamento de seus profissionais. Após a identificação destes aspectos, segue-se a caracterização e análise da população constituída pelos os estudantes da UNESP/Tupã, para verificar o grau das competências que possuem frente às principais características demandadas pelas organizações identificadas na literatura. 


\section{REFERENCIAL TEÓRICO}

\subsection{O ensino da Administração no Brasil}

Segundo Cunha (2009), o surgimento dos cursos de Administração no Brasil iniciou-se em 1952 com a criação da Escola Brasileira de Administração Pública da Fundação Getúlio Vargas (FGV). No entanto, o autor cita que a formação do administrador no Brasil já adquiria contornos claros na década de 40, advindo de uma necessidade de mão-de-obra qualificada no país, pois o mesmo superava o estágio de agrário para a industrialização.

Assim, nota-se que a busca pela qualificação já era considerada desde os primórdios do ensino da Administração no Brasil, impulsionada pela mudança e desenvolvimento social do país. Para Lacrus e Villela (2007), as condições e motivações para a disseminação dos cursos de Administração estão relacionadas ao caráter de especialização e complexidade, resultado dos processos de desenvolvimento dos países latino-americanos que consideravam que o desenvolvimento significava industrializar-se. Pode-se dizer desta forma, que no Brasil devido às transformações e novas necessidades socioeconômicas, foi necessário o investimento em mão-de-obra qualificada para dar suporte ao processo de industrialização. Fato iniciado devido ao crescimento econômico presente na década de 30 e, como conseqüência, o desenvolvimento do ensino superior de Administração a partir da década de 60 , juntamente com a tendência para geração de grandes empresas.

Em 2004 a quantidade de cursos de Administração no Brasil já alcançava 2.046 segundo dados obtidos no Relatório do Grupo de Trabalho, elaborado pela Secretaria de Educação Superior e o Ministério da Educação (SESu/MEC, 2004). O mesmo relatório apontava que em 1991 havia 333 cursos, resultando em um crescimento de $614 \%$ em pouco mais de uma década. O desenvolvimento desenfreado da quantidade de cursos de Administração no Brasil trouxe uma série de problemas resultantes da falta de planejamento e que acabou influenciando negativamente a qualidade do ensino, enviando para o mercado alunos sem o preparo necessário para suprir as necessidades dos contratantes.

Para Cunha (2009) o produto deste processo crescente é resultado do aumento da concentração de empresas e a burocratização, onde estas empresas à medida que crescem e modernizam-se, dão prioridade à mão de obra especializada em detrimento da mão-de-obra não qualificada. Portanto, o autor considera que o surto do ensino da Administração é decorrente do foco na tendência para a grande empresa, que passam a requerer pessoas de nível superior como sinônimo de qualificação profissional. 
Silva Reis (2003), em sua pesquisa cita aspectos de deficiência dos cursos de Administração dos Estados Unidos, apontados pela pesquisa de Bowditch e Bouno (1992) que se comparam com os observados no Brasil atualmente. Tais aspectos se resumem em: inabilidade para integração de funções empresariais; incapacidade para efetuar comunicação eficiente e eficaz; insensibilidade às pessoas que não têm a mesma formação; inabilidade no relacionamento pessoal; e grande dificuldade para trabalhar em grupo de modo eficaz.

Lacruz e Villela (2007) criticam o excesso de especialização dos conteúdos em diferentes disciplinas nos cursos de Administração, destacando o grau de não-integração das áreas do conhecimento, de forma com que o aluno não perceba a relação entre as variáveis de cada área. Também ressaltam o destaque excessivo aos aspectos instrumental do curso e insuficiente desenvolvimento das competências de caráter pessoal.

Portanto, não bastam para os Administradores apenas os conhecimentos obtidos na graduação, estes devem buscar o aprimoramento continuo de seus conhecimentos e desenvolvimento de suas competências, pois as empresas cada vez mais buscam profissionais qualificados e especializados decorrente da complexidade de gestão e da necessidade de tomar decisão e resolver problemas em um ambiente cada vez mais dinâmico.

\subsection{Perfil do Administrador demandado pelas empresas na nova dinâmica mundial}

Ao tratar sobre a sociedade capitalista atual e a globalização da economia, Lassance e Sparta (2003) ressaltam que as empresas, ao utilizarem um modelo enxuto de produção, tecnologias de ponta e a evolução na produção de bens não-materiais, como serviços e informações, geraram mudança nos postos de trabalhos e vem causando desemprego como resultado deste processo. Para as autoras, tais mudanças exigiram que os trabalhadores adquirissem novas habilidades para melhorarem seu grau de empregabilidade, como flexibilidade, polivalência, capacitação tecnológica e adaptabilidade, todas apoiadas na flexibilidade de produção e nas relações de trabalho, que passaram a ser guiadas pelas flutuações do mercado de consumo.

Segundo Omar Aktouf, professor da HEC Montreal, em obra de Davel e Milani (2005), trata ainda de uma pós-globalização, onde a economia mundial tenderia a uma "financeirização" das atividades e das trocas, entrando em um novo panorama da economia global. Neste sentido, a pós-globalização afetaria as empresas que teriam de adotar posturas distintas das tradicionais e dar mais 
importância ao emprego durável e qualificado, tratando os funcionários mais como investimentos em longo prazo, do que como simples recursos que tem de gerar resultados rápidos, ou como custos a serem cortados em momentos de crise.

Pochmann (2001) considera que as mudanças que estão reconfigurando as organizações e alterando o mercado de trabalho em todo o Brasil, estão associadas aos novos conhecimentos científicos e tecnológicos, que se aliam às novas exigências empresariais de contratação, como empregados polivalentes e multifuncionais, e maior nível de habilidades adicionais para o exercício do trabalho.

É nesse contexto que surge a figura do administrador moderno, que para atender às novas exigências empresariais, precisa aliar todo o conhecimento adquirido no curso de Administração com o desenvolvimento e capacitação de suas competências para suprir as novas necessidades das organizações, que exigem flexibilidade e velocidade de resposta como reação às constantes alterações de mercado.

Como estratégia para selecionar os candidatos de maiores competências, as organizações, em especial os departamentos de Recursos Humanos, estão adotando a estratégia de gestão de pessoas por suas competências. Parry (1996) resume o conceito de competência como sendo o conjunto de conhecimentos, habilidade e atitudes correlacionados, que influenciam diretamente nas atividades desenvolvidas e no desempenho da função.

Echeveste et al. (1999) trata sobre o tema, considerando que existem três blocos de atributos requeridos pelas empresas ao contratar administradores: atitudes/valores, habilidades/competências e conhecimentos. O primeiro diz respeito às características referentes a predisposição dos indivíduos, ou seja, como estes agem diante de determinada situação; sobre habilidades, o autor considera as aptidões e capacidades que influenciam no desempenho das atividades do administrador; e por último os conhecimentos, que são o conjunto de informações utilizadas como instrumento para que os executivos realizem suas tarefas e atendam às exigências demandadas. Para os autores, as competências requeridas para o mercado globalizado devem ser identificadas e desenvolvidas para o alcance de uma administração eficaz e contemporânea da nova ordem econômica. Definem as características gerais referentes a cada um dos blocos, exemplificadas no Quadro 1: 
Quadro 1 - Principais características definidas por Echeveste divididas por blocos

\begin{tabular}{|c|c|c|}
\hline Atitudes / Valores & Habilidades & Conhecimentos \\
\hline $\begin{array}{l}\text { Predisposição à } \\
\text { negociação }\end{array}$ & Dimensionamento do tempo & Perfil generalista \\
\hline $\begin{array}{l}\text { Predisposição para } \\
\text { correr riscos }\end{array}$ & $\begin{array}{l}\text { Coordenação de trabalhos em } \\
\text { equipe }\end{array}$ & Visão da empresa \\
\hline Criatividade & Gerenciamento da inovação & $\begin{array}{l}\text { Conhecimentos de negócios } \\
\text { internacionais }\end{array}$ \\
\hline Flexibilidade & $\begin{array}{l}\text { Integração das diversas áreas } \\
\text { funcionais }\end{array}$ & $\begin{array}{l}\text { Processos de alianças e joint } \\
\text { ventures }\end{array}$ \\
\hline Motivação & $\begin{array}{l}\text { Capacidade para tratar com } \\
\text { culturas diversas }\end{array}$ & Outros idiomas \\
\hline Intuição & $\begin{array}{l}\text { Antecipação de ameaças e } \\
\text { oportunidades }\end{array}$ & Tecnologia de informação \\
\hline Empreendedorismo & Capacidade de negociação & $\begin{array}{l}\text { Titulação em cursos de pós- } \\
\text { graduação }\end{array}$ \\
\hline $\begin{array}{l}\text { Ética profissional e } \\
\text { pessoal }\end{array}$ & Visão estratégica & $\begin{array}{l}\text { Cultura de outros países/ } \\
\text { vivência internacional }\end{array}$ \\
\hline Autoconfiança & Capacidade de delegação & Experiência \\
\hline Mobilidade pessoal & Capacidade de decisão & $\begin{array}{l}\text { Especialista com visão } \\
\text { sistêmica }\end{array}$ \\
\hline $\begin{array}{l}\text { Capacidade de } \\
\text { superação }\end{array}$ & Habilidade interpessoal & \\
\hline Abertura a novas ideias & Capacidade de liderança & \\
\hline Integridade & Agilidade & \\
\hline Humildade & Autogerenciamento & \\
\hline $\begin{array}{l}\text { Vontade de } \\
\text { autodesenvolvimento }\end{array}$ & Resolvedor de problemas & \\
\hline Atitude pró-ativa & Foco no resultado & \\
\hline Atitude reativa & Administrador de conflito & \\
\hline \multirow[t]{2}{*}{ Gosto pelo que faz } & Desenvolvedor de pessoas & \\
\hline & $\begin{array}{l}\text { Capacidade de viabilizar/ } \\
\text { implementar ideias }\end{array}$ & \\
\hline
\end{tabular}

Fonte: Elaborado pelos autores adaptado de Echeveste et al. (1999)

Ao pontuar diversas características que podem estar presentes no perfil do Administrador, o autor lista as principais aptidões do executivo no mercado globalizado expressas no Quadro 2: 
Quadro 2 - Principais características do perfil do executivo segundo Echeveste

\begin{tabular}{|l|l|}
\hline \multicolumn{2}{|c|}{ Principais atributos do executivo no mercado globalizado } \\
\hline 1. Integro & 7. Negociador \\
\hline 2. Dotado de visão estratégica & 8. Motivado \\
\hline 3. Conhecedor de sua empresa & 9. Coordenador de trabalhos em equipe \\
\hline 4. Possuidor de capacidade de decisão & 10. Hábil nas relações interpessoais \\
\hline 5. Focalizado no resultado & 11. Pró-ativo \\
\hline $\begin{array}{l}\text { 6. Ético no trato das questões profissionais } \\
\text { e sociais }\end{array}$ & 12. Empreendedor \\
\hline
\end{tabular}

Fonte: Elaborado pelos autores adaptado de Echeveste et al. (1999)

Silva, Santana e Pereira Neto (2010), em estudos mais recentes, também descrevem características exigidas para contratação de um Administrador: criatividade, inovação dos processos, honestidade, facilidade de raciocínio, empreendedorismo, eficiência, facilidade no relacionamento em equipe, caráter, formação técnico-acadêmica e o bom relacionamento com as pessoas, não necessariamente em sequência. Contudo, os autores também se referem a outros seis principais aspectos do perfil do Administrador, que foram identificados na primeira pesquisa sobre o Perfil do Administrador e de Mercado de Trabalho, publicada em 1995 pela Associação Nacional dos Cursos de Graduação em Administração (ANGRAD):

1) Formação humanista e visão global que habilite a compreender o meio social, político, econômico e cultural onde está inserido e a tomar decisões em um mundo diversificado;

2) Formação técnica e científica para atuar na administração das organizações, além de desenvolver atividades específicas da prática organizacional;

3) Internalização de valores de responsabilidade social, justiça e ética profissional;

4) Competência para empreender ações, analisando criticamente as organizações, antecipando e promovendo suas transformações;

5) Compreensão da necessidade do contínuo aperfeiçoamento profissional e do desenvolvimento da autoconfiança, e;

6) Atuação de forma interdisciplinar. 
A ANGRAD em parceria com os Conselhos Regionais de Administração (CRA) e o Conselho Federal de Administração (CFA) vem realizando durante os últimos anos pesquisas deste tipo que possuem grande importância porque permitem explorar aspectos relativos ao perfil, à formação, à identidade e às perspectivas profissionais do Administrador.

Lacruz e Villela (2007) caracterizam a evolução destes estudos ressaltando que a primeira pesquisa foi concebida e realizada em 1994 e publicada em 1995, a segunda concebida e executada em 1998 e publicada em 1999, a terceira atualizou e ampliou as anteriores, sendo coordenada pelo CFA e executada pela Fundação Instituto de Administração em 2003 e publicada em 2004. A quarta e última edição da pesquisa divulgada em 2006, ressalta de modo quantitativo quais seriam as características mais importantes para o Administrador, tanto na visão dos empregadores, dos professores Instituições de Ensino Superior (IES) e do próprio Administrador. Segundo a pesquisa, os dados foram obtidos com questionários para os graduados em Administração residentes no Brasil, professores que lecionam em cursos de Administração e organizações empregadoras de administradores no país, e foi obtido um retorno de 10.552 questionários, sendo 9.178 de administradores, 447 de empregadores e 927 de professores (CFA, 2006).

A pesquisa considerando a visão dos Administradores procurou identificar os principais aspectos que seus cursos de graduação haviam transmitido, com diversas opções de resposta e divididos em quatro blocos: Conhecimentos, Competências, Habilidades e Atitudes. Também foi considerada a visão dos docentes sobre o que consideravam mais importante integrar nas disciplinas e nos cursos, e aos empregadores o que reconheciam existir de mais importante nos Administradores de suas organizações. Os resultados da pesquisa organizados por blocos foram integrados e expostos na Tabela 1.

Como principais características identificadas nesta abordagem, observa-se a importância da visão do todo e do relacionamento interpessoal para o perfil do administrador, mas também fica explícita a necessidade de que estes saibam identificar problemas gerando estratégias para atingir a solução dos mesmos, estando relacionado com a visão sistêmica da organização e à administração dos recursos humanos da empresa. Portanto, torna-se necessária também a responsabilidade para assumir o processo decisório do planejamento e das ações estratégicas da empresa. Com relação às atitudes, comportamento ético, profissionalismo e comprometimento se consolidaram como os mais requisitados. 
Tabela 1 - Principais conhecimentos, habilidades, competências e atitudes do Administrador (CFA, 2006).

\begin{tabular}{lclc}
\hline Conhecimentos & (\%) & Habilidades & (\%) \\
\hline Administração de pessoas / equipes & 62,19 & Visão do todo & 74,04 \\
\hline Administração financeira e orçamentária & 60,19 & Relacionamento interpessoal & 71,5 \\
\hline Administração estratégica & 57,45 & Adaptação à transformação & 61,79 \\
\hline $\begin{array}{l}\text { Visão Ampla, profunda e articulada do } \\
\text { conjunto das áreas de conhecimento }\end{array}$ & 54,6 & Liderança & 61,07 \\
\hline Administração de vendas e marketing & 51,9 & Criatividade e inovação & 55,37 \\
\hline Competências & $\mathbf{( \% )}$ & Atitudes & (\%) \\
\hline $\begin{array}{l}\text { Identificar problemas, formular e implantar } \\
\text { soluçães }\end{array}$ & 71,19 & Comportamento ético & 75,21 \\
\hline $\begin{array}{l}\text { Desenvolver raciocínio lógico, crítico e } \\
\text { analítico sobre a realidade organizacional }\end{array}$ & 61,13 & Profissionalismo & 73,05 \\
\hline $\begin{array}{l}\text { Assumir o processo decisório das ações } \\
\text { de planejamento, organização, direção e } \\
\text { controle }\end{array}$ & 60,5 & Comprometimento & 71,16 \\
\hline $\begin{array}{l}\text { Desenvolver e socializar o conhecimento } \\
\text { alcançado no ambiente de trabalho }\end{array}$ & 54,91 & Aprendizado contínuo & 69,61 \\
\hline & 46,8 & $\begin{array}{l}\text { Atitude empreendedora/ } \\
\text { iniciativa }\end{array}$ & 62,32 \\
\hline \begin{tabular}{l} 
Elaborar e interpretar cenários \\
\hline
\end{tabular}
\end{tabular}

Fonte: Elaborado pelos autores, adaptado de CFA (2006).

$\mathrm{Na}$ análise da pesquisa observa-se que a mesma expõe de maneira distinta características referentes à 'competências' das demais características expostas anteriormente (conhecimentos, habilidades e atitudes), identificando um conflito teórico nas literaturas consultadas. Porém, para este trabalho será considerado que as competências são o conjunto dos três outros blocos de aspectos de perfil definido anteriormente. Não pretende-se tratar profundamente do conceito de competência nem da gestão por competências, pois como foi citado por Dutra, Hipólito e Machado Silva (2000), é grande a diversidade de interpretações deste conceito ao longo dos últimos trinta anos.

Dado todo este cenário de globalização e mudança da economia, resultando em novas exigências das empresas por perfil de funcionários qualificados, polivalentes e multifuncionais, julgou-se necessário também expor uma abordagem mundial referente a este novo perfil de Administrador demandado pelo mercado. McLoughlin (2005) em seu artigo trata de um estudo de negócios 
realizado pela consultoria Assignment Plus, sobre as empresas líderes em todo o mundo, e identifica uma série de características definidoras de um gerente sênior de sucesso, que foram traduzidas, organizadas e expostas no Quadro 3:

\section{Quadro 3 - Características de um gerente sênior de sucesso, segundo estudos da Assignment Plus}

\begin{tabular}{|c|c|c|}
\hline $\begin{array}{l}\text { Ter um conhecimento real da } \\
\text { empresa, empatia com a sua } \\
\text { missão e um compromisso } \\
\text { genuíno com seus objetivos } \\
\text { e valores; }\end{array}$ & $\begin{array}{l}\text { Ter uma abordagem } \\
\text { disciplinada e metódica para } \\
\text { lidar com vários projetos } \\
\text { simultaneamente; }\end{array}$ & $\begin{array}{l}\text { Gerencia os recursos de forma } \\
\text { eficaz }\end{array}$ \\
\hline $\begin{array}{l}\text { Ter experiência direta } \\
\text { significativa do negócio e } \\
\text { um registro comprovando o } \\
\text { sucesso na área relevante de } \\
\text { gestão; }\end{array}$ & $\begin{array}{l}\text { Ter a confiança e a habilidade } \\
\text { de priorizar e resolver uma } \\
\text { vasta gama de objetivos e } \\
\text { problemas; }\end{array}$ & $\begin{array}{l}\text { Tem a capacidade de se } \\
\text { envolver com indivíduos e } \\
\text { grupos em uma variedade de } \\
\text { níveis e de meios de grande } \\
\text { alcance; }\end{array}$ \\
\hline $\begin{array}{l}\text { É um negociador articulado e } \\
\text { persuasivo, com habilidades } \\
\text { influenciadoras dinâmica; }\end{array}$ & $\begin{array}{l}\text { Ter auto-confiança e } \\
\text { capacidade de tomar a } \\
\text { iniciativa, quando necessário; }\end{array}$ & $\begin{array}{l}\text { É atualizado nos } \\
\text { conhecimentos de Informática } \\
\text { e possui habilidades de } \\
\text { pesquisa na Web; }\end{array}$ \\
\hline $\begin{array}{l}\text { É um pensador lógico } \\
\text { com habilidades analíticas } \\
\text { estratégicas e pragmáticas. } \\
\text { Tem uma abordagem } \\
\text { inovadora, imaginativa } \\
\text { e criativa para resolver } \\
\text { problemas; }\end{array}$ & $\begin{array}{l}\text { Adapta-se facilmente às } \\
\text { novas funções, métodos e } \\
\text { situações. É flexível, aberto e } \\
\text { sensível às novas idéias; }\end{array}$ & $\begin{array}{l}\text { Possui excelente capacidade } \\
\text { de gestão de tempo e } \\
\text { demonstra um compromisso } \\
\text { real com a melhoria contínua; }\end{array}$ \\
\hline $\begin{array}{l}\text { Prospera em um ambiente } \\
\text { de trabalho exigente e tem } \\
\text { o compromisso de definir e } \\
\text { cumprir prazos apertados; }\end{array}$ & $\begin{array}{l}\text { Possui excelente habilidade } \\
\text { de comunicação verbal e } \\
\text { escrita, podendo assimilar } \\
\text { e traduzir informações } \\
\text { complexas em formato } \\
\text { conciso e lúcido; }\end{array}$ & $\begin{array}{l}\text { É apaixonadamente } \\
\text { comprometido com } \\
\text { atendimento ao cliente de alta } \\
\text { qualidade e excelência do } \\
\text { serviço; }\end{array}$ \\
\hline
\end{tabular}

Fonte: adaptado de McLoughlin (2005).

Observa-se no Quadro 3 que muitas das aptidões identificadas coincidem com as identificadas anteriormente por estudos realizados no Brasil (relação interpessoal, empreendimento, negociação), diferenciando-se apenas ao tratar detalhadamente de competências mais técnicas e específicas, como lidar com vários projetos simultaneamente de maneira disciplinada e metódica, possuir habilidades de pesquisa na Web e ter habilidade de comunicação verbal e escrita. Além destes, todos os aspectos identificados pela pesquisa e expostos por MacLoughlin (2005), foram observados de alguma forma nos definidos pelos autores brasileiros. 
Em nível mundial, as empresas de países com economia mais desenvolvida já demandam aspectos de perfil mais específicos, referentes à tecnologia e informação, ao tratar de habilidades referentes à Internet e Comunicação. Nunes (2004) em sua obra trata da rápida difusão das tecnologias da informação e comunicação e das mudanças que esta vem causando para a sociedade, a ponto de se considerar um novo modelo de sociedade, a sociedade da informação. Neste contexto fica exposta a necessidade de desenvolvimento das empresas para conseguirem se adaptar a este novo ambiente, onde a tecnologia aumenta a competitividade entre as empresas e revoluciona a sociedade.

Miranda et al. (2006) ressalta em sua obra que a indústria, o comércio, o setor educacional e os setores de serviços e entretenimento estão criando uma dependência em relação aos recursos de TI, consequentemente pressionando as organizações a se adaptarem e conviverem com este novo modelo de comportamento e aprendizagem. O Autor deixa clara a necessidade do domínio da tecnologia para os profissionais atuais, confirmada por Rifkin (2001) que afirma que o uso de tecnologias é fundamental, pois permite a participação de redes de relacionamento e maior acesso à cultura, ao trabalho e vida social.

Portanto, neste contexto surge mais uma vez um desafio que está virando questão de sobrevivência para as organizações, as novas tecnologias implicam em novas formas de comunicação, criação e fabricação. Em resumo, a tecnologia e as ferramentas de TI servem de auxílio para os Administradores no gerenciamento da informação e na comunicação dentro e fora da organização. Porém, não basta só a habilidade para lidar com estas ferramentas, como surge também a necessidade do desenvolvimento de maiores habilidades comunicativas, para que o Administrador possa difundir o conhecimento e gerenciar as informações dentro do meio social ou organizacional.

Curvello (2002) refere-se aos estudos que analisam a introdução de novas tecnologias sobre a vida organizacional causando impacto sobre o modelo de comunicação nas empresas atuais. Afirma que a nova era da interatividade confere maior poder ao processo comunicativo, exigindo maiores habilidades comunicativas por parte do administrador e do profissional de comunicação, pois hoje em dia a maioria das estruturas de comunicação nas grandes organizações brasileiras encontra-se sob uma arquitetura de integração de processos e atividades, conferindo maior complexidade a relações de comunicação.

A evolução das Tecnologias da Informação e Comunicação (TIC) está aumentando a concorrência entre as empresas e vem gerando a necessidade do aperfeiçoamento de outra competência para os administradores, além das relacionadas à Informática, que atua tanto como facilitadora das ferramentas 
tecnológicas quanto de incremento nas habilidades de comunicação do Administrador, que é o conhecimento de uma ou mais línguas estrangeiras.

Com a Globalização a interação entre empresas de países diferentes é cada vez maior, surgindo então a necessidade do conhecimento de uma língua estrangeira, em especial o idioma Inglês. Mello (2010) cita um levantamento realizado pela consultoria Bernt Entschev Human Capital, que relata que mais de $64 \%$ das contratações a níveis gerenciais desde o começo do ano, exigiam o domínio do idioma Inglês.

Gonçalves (2009) afirma o fato da língua inglesa ser tão requisitada é resultado do domínio que a economia mundial possui dos Estados Unidos e Inglaterra, e mesmo com o avanço da China, a habilidade de entender, escrever e falar inglês ainda será requisito básico para uma boa carreira profissional. Mello (2010) também cita que na pesquisa realizada pela consultora Bernt, as duas línguas mais procuradas após o inglês são o Espanhol e o Alemão, porém ainda com baixa representatividade frente à língua inglesa.

\section{MATERIAL E MÉTODO}

\subsection{Procedimento metodológico}

Para identificar os principais requisitos demandados pelas empresas atualmente no momento da contratação de um administrador, a priori foi realizada uma pesquisa teórica de caráter qualitativo, que procurou abordar diversas visões sobre o perfil do administrador moderno. O conhecimento foi obtido por meio de um levantamento bibliográfico que abordasse temas como a formação do perfil de alunos e profissionais de Administração, o ensino nacional de Administração e os requisitos demandados pelas empresas.

Também com o objetivo de pontuar os principais aspectos profissionais demandados, foi realizada uma pesquisa documental nas oportunidades de estágios e empregos de empresas divulgadas pelo Balcão de Estágios e Empregos do Campus da UNESP/Tupã, contabilizando os pré-requisitos de cada uma das 35 oportunidades, obtendo no final a identificação dos principais aspectos considerados para a contratação. O Balcão de Estágios e Empregos é um projeto de extensão que atua de forma a aproximar as empresas dos alunos, divulgando oportunidades e armazenando currículos dos estudantes que procuram por estágios ou empregos. A pesquisa documental tornou possível a identificação de algumas competências que as empresas têm como pré-requisito no momento da contratação e serviram de auxilio na elaboração do questionário aplicado aos alunos. 
Após o levantamento teórico, foram identificadas oito principais características que os administradores devem possuir para suprir a demanda de profissionais pelas empresas, características estas que foram consideradas no questionário e utilizadas para a análise de caráter descritiva do perfil dos alunos da UNESP/Tupã, verificando o grau com que cada competência se manifestava nos estudantes, levando em conta a diferença entre alunos do período Diurno e Noturno, e o termo em que estes se encontravam $\left(3^{\circ}, 5^{\circ}\right.$ e $\left.7^{\circ}\right)$.

\subsection{Instrumentos de coletas de dados e ferramental de análise}

O instrumento de coleta de dados primários foi questionário do tipo survey, que abordava questões como a caracterização dos alunos em gênero, idade, turno e termo, o conhecimento em línguas estrangeiras e informática, as expectativas em relação ao mercado de trabalho e outras informações.

Também foram expostas nos questionários as principais competências comportamentais pesquisadas e identificadas, em escala de Likert, onde os alunos se avaliaram em pontos de 1 a 5 cada uma de suas competências, consideradas posteriormente em escalas como baixo (1-2), médio (3) e alto (4-5) o grau da competência em questão.

Os questionários foram aplicados via censo nas seis turmas de alunos do curso de Administração, sendo duas turmas do $3^{\circ}$ semestre, duas do $5^{\circ}$ semestre e duas do $7^{\circ}$ semestre, diurno e noturno respectivamente, resultando em um total de 186 questionários respondidos. A etapa anterior à aplicação dos questionários foi marcada pela realização do teste-piloto, a fim de identificar possíveis falhas, com a participação de dois alunos por semestre e por turno diferenciadamente, totalizando 12 questionários de teste-piloto.

Após a aplicação do instrumento de coleta dos dados primários, foi realizada a tabulação dos questionários e os dados foram inseridos em um Banco de Dados Firebird 1.6, onde as correlações foram feitas via consultas SQL e materializadas em tabelas com as referidas variáveis.

\subsection{Descrição do objeto de estudo}

De acordo com informações da UNESP (2011a), a universidade é uma das mais importantes do país se destacando tanto no ensino, pesquisa e extensão de serviços à comunidade. É uma das três universidades públicas mantidas pelo Governo do Estado de São Paulo ao lado da Universidade de São Paulo (USP) e Universidade Estadual de Campinas (Unicamp). Criada em 1976, a UNESP 
possui uma peculiaridade que a distingue das demais, que é a de estar presente em praticamente todo o estado, distribuída em 21 unidades no Interior, um na Capital e um no Litoral Paulista, oferecendo 168 opções de cursos de graduação em 64 carreiras de nível superior e 112 programas de pós-graduação.

De acordo com Oliveira e Pinto (2010), o Campus Experimental de Tupã (UNESP/Tupã ou CET) localizado em Tupã, iniciou suas atividades em 2003 com a implantação do Curso de Administração, sendo um dos oito cursos criados a partir de um Plano de Expansão da UNESP iniciado em 2002. Nesta expansão foram criadas sete novas unidades localizadas em cidades do interior paulista, recebendo o nome de Unidades Diferenciadas e, posteriormente, se tornaram Campi Experimentais.

Oliveira e Pinto (2010) afirmam que esta expansão atendia a duas premissas básicas: a de implantar cursos inéditos para suprir novas demandas e preencher lacunas em áreas da Universidade em regiões distintas do Estado; e de implantar instituições públicas de ensino superior de qualidade em regiões carentes, inclusive do ponto de vista socioeconômico.

No ano de 2011, o curso de Administração da UNESP/Tupã contava com seis turmas de que continham em média 40 alunos, das quais três freqüentam o período diurno e três o período noturno. Segundo o site da instituição (UNESP, 2011b), a implantação da Universidade é considerada por autoridades e população da cidade como a retomada do desenvolvimento educacional e cultural do município, que no passado ostentava o título de Metrópole Universitária do Centro Oeste Paulista.

\section{RESULTADOS E DISCUSSÃO}

\subsection{Principais competências demandadas para o perfil do administrador}

Pode-se observar na revisão da literatura consultada que devido à globalização e aos atuais acontecimentos mundiais, o mercado atual exige cada vez mais flexibilidade e velocidade de resposta das organizações frente aos fatores da nova dinâmica mundial, resultando na demanda por profissionais mais flexíveis, multiqualificados e multifuncionais, influenciando na mudança do perfil dos administradores procurados pelas empresas atuais.

Com o objetivo de identificar os principais aspectos do perfil do administrador demandado pelas empresas, foi realizada inicialmente uma pesquisa no banco de dados de oportunidades de estágios e empregos do Projeto de Exten- 
são da UNESP/Tupã denominado "Balcão de Estágio e Empregos", onde os requisitos e aspectos demandados pelas empresas nas oportunidades de estágio/ trainee/emprego foram contabilizados e expostos na Figura 1. Posteriormente, foi possível questionar os discentes da UNESP/Tupã sobre tais quesitos, verificando se os alunos encontram-se preparados para suprir as novas exigências do mercado.

\section{Figura 1 - Requisitos mais demandados nas oportunidades do Balcão de Estágio}

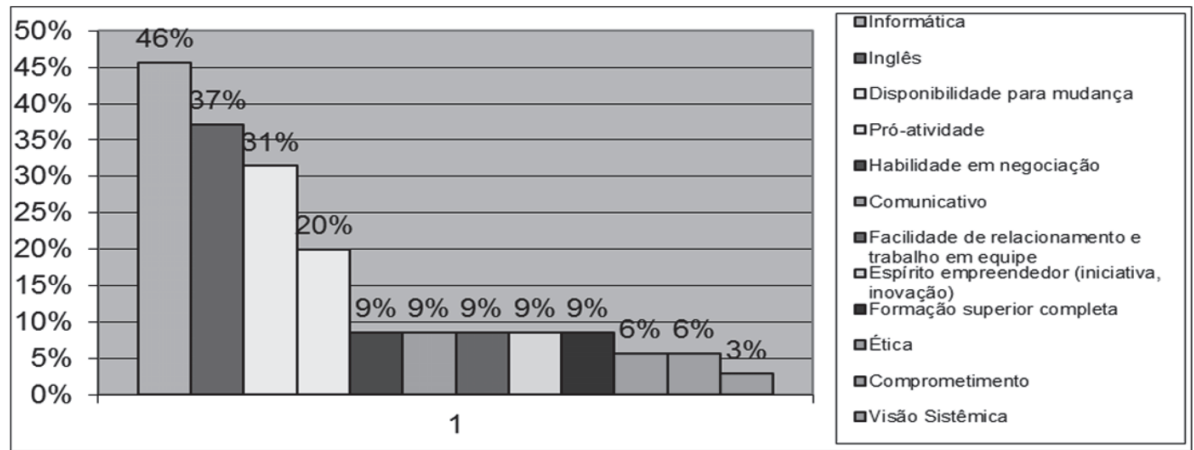

Fonte: Elaborado pelos autores.

Observa-se na Figura 1 que os requisitos mais demandados foram o conhecimento em Informática apontado em $46 \%$ das oportunidades e a Língua Inglesa em $37 \%$. É interessante notar que o terceiro requisito com maior frequência nas oportunidades era a 'Disponibilidade para mudança', que pode ser justificado pela maior dinâmica da economia atual, da necessidade de maior flexibilidade das empresas e da maior procura por profissionais qualificados, que muitas vezes encontram-se distantes do local onde as empresas estão instaladas. As demais características aproximam-se mais das observadas na revisão teórica, como a pró-atividade, negociação, relacionamento com as pessoas, entre outras.

Para identificar quais são as principais competências demandadas pelas empresas foi elaborado um quadro que integra e sintetiza todas as abordagens observadas na literatura com os aspectos levantados na pesquisa do Balcão de Estágios, conforme Figura 2. 
Figura 2 - Integração das abordagens apontadas na literatura com levantamentos do Balcão de Estágio

\begin{tabular}{|c|c|c|c|c|c|c|c|}
\hline Características principais do Administrador & 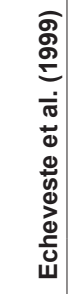 & 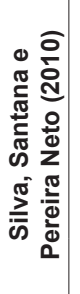 & 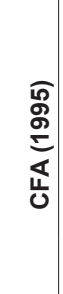 & 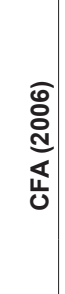 & 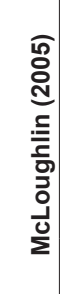 & 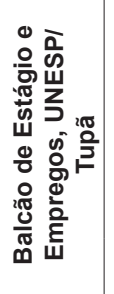 & 흄 \\
\hline $\begin{array}{l}\text { Capacidade para empreender (inovação e } \\
\text { iniciativa) e tomar decisões }\end{array}$ & $\mathbf{x}$ & $\mathbf{x}$ & $\mathbf{x}$ & $\mathbf{x}$ & $\mathbf{x}$ & $\mathbf{x}$ & 6 \\
\hline $\begin{array}{l}\text { Capacidade para atuar em equipes e boa } \\
\text { relações interpessoal }\end{array}$ & $\mathbf{x}$ & $\mathbf{x}$ & & $\mathbf{x}$ & $\mathbf{x}$ & $\mathbf{x}$ & 5 \\
\hline $\begin{array}{l}\text { Valores (Integro, ético, honesto, caráter, } \\
\text { Comprometimento, Profissionalismo, outras) }\end{array}$ & $\mathbf{x}$ & & $\mathbf{x}$ & $\mathbf{x}$ & $\mathbf{x}$ & $\mathbf{x}$ & 5 \\
\hline $\begin{array}{l}\text { Visão sistêmica dos fatos e ligação com os } \\
\text { aspectos organizacionais }\end{array}$ & $x$ & & $\mathbf{x}$ & $\mathbf{x}$ & & $\mathbf{x}$ & 4 \\
\hline $\begin{array}{l}\text { Flexibilidade e pró-atividade diante das } \\
\text { mudanças organizacionais }\end{array}$ & $\mathbf{x}$ & & & $\mathbf{x}$ & $\mathbf{x}$ & $\mathbf{x}$ & 4 \\
\hline Capacidade de negociação & $\mathbf{x}$ & $\mathbf{x}$ & & & $\mathbf{x}$ & $\mathbf{x}$ & 3 \\
\hline Facilidade de raciocínio lógico & & $x$ & & $\mathbf{x}$ & $\mathbf{x}$ & & 3 \\
\hline Formação técnica-acadêmica & & $\mathbf{x}$ & $x$ & & & $\mathbf{x}$ & 3 \\
\hline Capacidade comunicativa & & & & & $\mathbf{x}$ & $\mathbf{x}$ & 2 \\
\hline Conhecedor de sua empresa & $x$ & & & & $\mathbf{x}$ & & 2 \\
\hline Visão Estratégica & $\mathbf{x}$ & & & $\mathbf{x}$ & & & 2 \\
\hline Eficiência & & $\mathbf{x}$ & & & $\mathbf{x}$ & & 2 \\
\hline $\begin{array}{l}\text { Compreensão da necessidade do contínuo } \\
\text { aperfeiçoamento profissional }\end{array}$ & & & $\mathbf{x}$ & $\mathbf{x}$ & & & 2 \\
\hline Focalizado no resultado & $\mathbf{x}$ & & & & & & 1 \\
\hline Atuar de forma interdisciplinar & & & $\mathbf{x}$ & & & & 1 \\
\hline Liderança & & & & $\mathbf{x}$ & & & 1 \\
\hline Desenvolver e socializar o conhecimento & & & & $\mathbf{x}$ & & & 1 \\
\hline Experiência com o negócio & & & & & $x$ & & 1 \\
\hline $\begin{array}{l}\text { Capacidade de atuar com prazos apertados e } \\
\text { boa gestão do tempo }\end{array}$ & & & & & $\mathbf{x}$ & & 1 \\
\hline $\begin{array}{l}\text { Abordagem disciplinada e metodológica para } \\
\text { lidar com vários projetos simultaneamente }\end{array}$ & & & & & $\mathbf{x}$ & & 1 \\
\hline Resolver vários problemas simultaneamente & & & & & $\mathbf{x}$ & & 1 \\
\hline Habilidades com pesquisas na Web & & & & & $\mathbf{x}$ & & 1 \\
\hline
\end{tabular}

Fonte: Elaborado pelos autores. 
Para a identificação das principais competências demandadas, foram considerados os aspectos mais apontados na literatura, de acordo com a frequência. As características identificadas foram inseridas no questionário aplicado aos alunos que realizaram uma auto-avaliação utilizando escala Likert ${ }^{1}$ de $1-5$, traduzidos pelos extremos de baixo a alto grau de manifestação.

$\mathrm{Na}$ elaboração da Figura 2 , todas as características relacionadas aos aspectos de valores profissionais, foram sintetizadas apenas como 'valores', demonstrando a grande importância que este requisito possui para compor as competências profissionais. Porém, como se trata de características mais relacionadas à personalidade (ética, honestidade, etc.) não foram utilizadas na análise. Considerou-se que tais características seriam extremamente subjetivas para o instrumento de análise em questão. Outro aspecto desconsiderado para a análise foi a 'formação técnica acadêmica', pois como a pesquisa foi feita com alunos, nenhum havia completado sua formação, mas em geral é também considerado um ponto importante observado nos estudos.

Com a análise da Figura 2, observa-se então que a 'capacidade para empreender e tomar decisões' foi a mais frequentemente citada, que considera além da tomada de decisão, características como inovação e iniciativa que também estão inclusas nesta competência. Em seguida, as competências identificadas com maior frequência e de maior importância foram: 'capacidade de atuar em equipe e boa relação interpessoal'; 'flexibilidade e pró-atividade diante das mudanças organizacionais'; e a 'visão sistêmica dos fatos e ligação com os aspectos organizacionais'.

Outras competências também foram observadas com frequência relevante, tais como a 'capacidade de negociação' e a 'facilidade de raciocínio lógico', porém no questionário aplicado apenas a 'capacidade de negociação' foi considerada. Como último aspecto considerado está a 'capacidade comunicativa', que mesmo obtendo uma frequência baixa na integração das abordagens, nos estudos observou-se a tendência de que esta competência será cada vez mais exigida com o desenvolvimento econômico e a globalização.

Por último, a necessidade de conhecimentos em informática e outros idiomas também foram identificados como fundamentais para que os administradores atendam ao perfil demandado, justificado tanto pela literatura quanto pela representatividade que tiveram nas oportunidades observadas do Balcão de Estágios.

Sendo assim, as oito principais características do perfil do administrador observadas na pesquisa e consideradas no questionário para a análise dos alunos

1 A escala Likert é uma escala ordinal qualitativa, onde se é possível comparar uma característica qualitativa com uma referência numérica (um parâmetro mensurável). 
foram: 1) Capacidade para empreender e tomar decisões; 2) Capacidade para atuar em equipes e boa relação interpessoal; 3) Flexibilidade e pró-atividade diante das mudanças organizacionais; 4) Visão sistêmica dos fatos e ligação com aspectos organizacionais; 5) Capacidade de negociação; 6) Capacidade comunicativa; 7) Conhecimentos em informática e 8) Conhecimento de outros idiomas (em especial o inglês).

\subsection{Análises das principais competências dos estudantes da UNESP/Tupã}

A população de estudantes analisada corresponde a um total de 186 alunos, dos quais $51 \%$ são do gênero masculino e $49 \%$ do gênero feminino, não resultando em diferença considerável. Porém, observa-se que existe uma pequena diferença na quantidade de alunos que participaram da pesquisa com relação ao período, onde o noturno teve maior quantidade de alunos que responderam os questionários, tornando assim a característica geral da população com maior influência dos alunos do período da noite. Em relação à participação dos alunos segmentando por gênero, período e termo, verifica-se uma predominância de alunos do $3^{\circ}$ semestre do gênero masculino e do $5^{\circ}$ semestre do gênero feminino, porém uma participação reduzida de mulheres entre alunos do $7^{\circ}$ semestre (vide Tabela 2).

Tabela 2 - Caracterização da população estudada

\begin{tabular}{lcccccc} 
& \multicolumn{3}{c}{ Masculino (95) } & \multicolumn{3}{c}{ Feminino (91) } \\
\cline { 2 - 7 } & $\mathbf{3}^{\circ}$ semestre & $\mathbf{5}^{\circ}$ semestre & $\mathbf{7}^{\circ}$ semestre & $\mathbf{3}^{\circ}$ semestre & $\mathbf{5}^{\circ}$ semestre & $\mathbf{7}^{\circ}$ semestre \\
\hline Diurno & $9 \%$ & $6 \%$ & $6 \%$ & $8 \%$ & $11 \%$ & $5 \%$ \\
\hline Noturno & $11 \%$ & $8 \%$ & $11 \%$ & $9 \%$ & $10 \%$ & $6 \%$ \\
\hline Total & $\mathbf{2 0} \%$ & $\mathbf{1 4 \%}$ & $\mathbf{1 7 \%}$ & $\mathbf{1 7 \%}$ & $\mathbf{2 1 \%}$ & $\mathbf{1 1 \%}$ \\
\hline
\end{tabular}

Fonte: Elaborado pelos autores

Para melhor caracterização da população estudada e para auxiliar no entendimento e na análise das competências, verificou-se também a parcela de alunos que já estão em alguma atividade como estágio ou emprego, considerando que este fator poderia explicar e justificar um maior ou menor grau de certa competência por parte de períodos ou termos diferentes. Sendo assim, 
observou-se que existe uma grande diferença quando comparados os períodos, enquanto no diurno $13 \%$ dos alunos já trabalham ou realizam estágio, no noturno este valor corresponde a $40 \%$ dos estudantes. Analisando por termo verifica-se um aumento da porcentagem com o passar dos semestres, porém desuniforme, sendo que existem mais alunos do $3^{\circ}$ semestre $(26 \%)$ que estão em atividade do que alunos do $5^{\circ}$ semestre $(21 \%)$, mas o $7^{\circ}$ semestre possui a grande maioria com $39 \%$ dos alunos já em atividade.

Como início da análise das competências dos estudantes da UNESP/ Tupã, foram expostos primeiramente os aspectos referentes ao quadro elaborado com a comparação das abordagens e os requisitos de maior importância identificados pela pesquisa. Para a análise destas competências foi considerado a auto avaliação dos alunos em uma escala de Likert, que de 1-5 verificava o grau com que cada competência se manifestava em cada estudante, sendo 1 e 2 baixo, 3 médio, 4 e 5 considerado alto grau da competência em questão.

Em relação aos alunos do $3^{\circ}$ semestre, todas as competências foram consideradas como de alto grau, mas manifestando-se em maior representatividade nos aspectos de 'trabalho em equipe' e 'negociação', demonstrado na Tabela 3 .

Tabela 3 - Principais competências do administrador e o grau de manifestação nos alunos do $3^{\circ}$ semestre

\begin{tabular}{lccc}
\hline C. Comportamentais $\left(\mathbf{3}^{\circ}\right.$ semestre) & Baixo (1+2) & Médio (3) & Alto (4+5) \\
\hline Flexibilidade e Pró-atividade & $5 \%$ & $35 \%$ & $60 \%$ \\
\hline Empreender e Tomar decisões & $2 \%$ & $46 \%$ & $52 \%$ \\
\hline Trabalho em equipe & $9 \%$ & $26 \%$ & $65 \%$ \\
\hline Comunicação & $8 \%$ & $34 \%$ & $58 \%$ \\
\hline Visão Sistêmica & $3 \%$ & $38 \%$ & $58 \%$ \\
\hline Negociação & $6 \%$ & $32 \%$ & $62 \%$ \\
\hline
\end{tabular}

Fonte: Elaborada pelos autores

Nos alunos do $5^{\circ}$ semestre o mesmo acontece de grande maioria se considerar em um alto grau para todas as competências. Porém, neste caso os aspectos que se destacaram foram a 'Flexibilidade e Pró-atividade' e também o 'Trabalho em Equipe', conforme Tabela 4. 
Tabela 4 - Principais competências do administrador e o grau de manifestação nos alunos do $5^{\circ}$ sem.

\begin{tabular}{|c|c|c|c|}
\hline C. Comportamentais $\left(5^{\circ}\right.$ semestre) & Baixo $(1+2)$ & Médio (3) & Alto $(4+5)$ \\
\hline Flexibilidade e Pró-atividade & $5 \%$ & $26 \%$ & $70 \%$ \\
\hline Empreender e Tomar decisões & $8 \%$ & $38 \%$ & $55 \%$ \\
\hline Trabalho em equipe & $2 \%$ & $26 \%$ & $72 \%$ \\
\hline Comunicação & $6 \%$ & $39 \%$ & $55 \%$ \\
\hline Visão Sistêmica & $3 \%$ & $45 \%$ & $52 \%$ \\
\hline Negociação & $11 \%$ & $35 \%$ & $55 \%$ \\
\hline
\end{tabular}

Fonte: Elaborada pelos autores

No $7^{\circ}$ semestre não foi diferente, todas as competências foram consideradas como um alto grau de manifestação nos alunos deste termo, tendo como principais o 'Trabalho em equipe' e a 'Visão Sistêmica' (vide Tabela 5).

Tabela 5 - Principais competências do administrador e o grau de manifestação nos alunos do $7^{\circ}$ sem.

\begin{tabular}{lccc}
\hline C. Comportamentais $\left(\mathbf{7}^{\mathbf{0}}\right.$ semestre) & Baixo (1+2) & Médio (3) & Alto (4+5) \\
\hline Flexibilidade e Pró-atividade & $2 \%$ & $28 \%$ & $70 \%$ \\
\hline Empreender e Tomar decisões & $4 \%$ & $30 \%$ & $67 \%$ \\
\hline Trabalho em equipe & $2 \%$ & $21 \%$ & $77 \%$ \\
\hline Comunicação & $2 \%$ & $33 \%$ & $65 \%$ \\
\hline Visão Sistêmica & $0 \%$ & $26 \%$ & $74 \%$ \\
\hline Negociação & $0 \%$ & $44 \%$ & $56 \%$ \\
\hline
\end{tabular}

Fonte: Elaborada pelos autores

O que se pode observar como relevante nesta análise é que no contexto geral, todos os aspectos tiveram uma porcentagem maior de alto grau de manifestação nos alunos do $7^{\circ}$ semestre, comprovando uma evolução das competências com o passar do curso e desenvolvimento de outras atividades de aprimoramento por parte dos alunos. 
A representatividade da 'Visão Sistêmica' nos alunos do $7^{\circ}$ semestre pode ser justificada pela maior maturidade e o grau de conhecimento que estes já obtiveram com o passar do curso. Outro ponto importante foi o alto grau de competência para 'Trabalho em equipe' em todos os semestres, que pode ser explicado pelo fato especial do curso de Administração da UNESP/Tupã possuir em sua grade uma matéria interdisciplinar chamada de Trabalho Interdisciplinar Orientado (TIO), que permite com que os alunos trabalhem em grupos desde o início do curso, gerenciando conflitos e realizando trabalhos com abordagens interdisciplinares, em um contexto atual que se critica o excesso de especialização entre as áreas do conhecimento nos cursos de Administração, que prejudica na capacidade deste profissional atuar como articulador da organização.

Para a análise das competências considerando a diferença entre os alunos do diurno e do noturno, foram somados os índices 4 e 5 considerados de alto grau para cada competência, e posteriormente identificado a diferença entre os períodos para cada aspecto. Em geral, as competências com maior representatividade foram 'Trabalho em equipe' mais uma vez e 'Flexibilidade e pró-atividade'. Porém, o diurno se destaca também no aspecto da 'Negociação' e o noturno em 'Visão Sistêmica' (vide Tabela 6).

Tabela 6 - Diferença entre o alto grau de competência dos alunos por período

Somatório dos índices 4 e 5

\begin{tabular}{lccc}
\cline { 2 - 4 } & Diurno (D) & Noturno (N) & Diferença (D-N) \\
\hline Flexibilidade e Pró-atividade & $70 \%$ & $64 \%$ & $+6 \%$ \\
\hline Empreender e Tomar decisões & $55 \%$ & $59 \%$ & $-4 \%$ \\
\hline Trabalho em equipe & $72 \%$ & $70 \%$ & $+2 \%$ \\
\hline Comunicação & $58 \%$ & $60 \%$ & $-2 \%$ \\
\hline Visão Sistêmica & $58 \%$ & $63 \%$ & $-5 \%$ \\
\hline Negociação & $65 \%$ & $51 \%$ & $+14 \%$ \\
\hline
\end{tabular}

Fonte: Elaborado pelos autores

Não foi verificada grande diferença entre as competências com exceção da 'Capacidade de Negociação' e 'Flexibilidade e pró-atividade', onde os alunos do diurno tiveram uma superioridade principalmente no que diz respeito à 'negociação'. Porém, não se identificou justificativas para esta competência se manifestar tão mais alta nos alunos do diurno. A baixa diferença entre "trabalho 
em equipe' e 'comunicação' pode ser explicada pelo fato do curso possibilitar o desenvolvimento de trabalhos em equipe e apresentações dos mesmos em forma de seminários que favorecem no aperfeiçoamento destas competências em ambos os períodos.

Em especial à 'Capacidade Comunicativa', verifica-se que apesar de se manifestar quase igualmente nos dois períodos, esta ainda possui baixa representatividade se comparada com as demais, assim como a 'tomada de decisão', mas esta última pode ser justificada por este aspecto ser mais desenvolvido quando o profissional já estiver em atividade, por isso esta competência se manifesta em maior grau no período noturno, que possui mais alunos em estágios e empregos.

Dentre as principais competências necessárias para um administrador ingressar com sucesso no mercado de trabalho, também estão presentes com bastante representatividade, os conhecimentos em informática e em diferentes idiomas, especialmente o inglês.

No questionário aplicado, os níveis de conhecimento nestes aspectos foram divididos em 'nenhum', 'básico', ‘intermediário' e 'avançado', diferente da escala Likert adotada anteriormente. No que tange a conhecimento em informática, o resultado entre os turnos foram bastante simétricos, indicando que a maioria dos graduandos possui nível intermediário em informática. Porém no período noturno, 35\% responderam que possuem conhecimentos avançados, enquanto no diurno apenas $23 \%$ responderam a essa opção, indicando assim, que o noturno possui maior nível de conhecimento de informática (vide Tabela 7).

Essa maior habilidade de conhecimentos em informática no período noturno se deve a maioria de seus integrantes já estar atuando no mercado de trabalho, o que exige maior domínio na habilidade e demanda maior atualização sobre esse conhecimento.

Tabela 7 - Nível do conhecimento em Informática dos alunos por período

\begin{tabular}{lcccc}
\hline Nível Informática & Básico & Intermediário & Avançado & Nenhum \\
\hline Diurno & $24 \%$ & $52 \%$ & $23 \%$ & $1 \%$ \\
\hline Noturno & $16 \%$ & $46 \%$ & $35 \%$ & $3 \%$ \\
\hline
\end{tabular}

Fonte: Elaborado pelos autores

Com relação à análise de conhecimento de informática entre os semestres, observou-se que no $3^{\circ}$ semestre, $32 \%$ dos alunos possuem conhecimento básico em informática (vide Tabela 8 ). No $5^{\circ}$ semestre essa porcentagem reduz para 
$17 \%$, e no $7^{\circ}$ semestre o índice de informática básica cai para $7 \%$, o que indica que no decorrer da graduação os alunos aprimoram seus conhecimentos através de disciplinas relacionadas ao assunto, cursos extracurriculares e também pela inserção no mercado de trabalho, que por sua vez, exige esse conhecimento e mantém o aluno mais próximo da prática enquanto desenvolve suas atividades de trabalho. Um ponto importante é que mais da metade dos alunos do $7^{\circ} \mathrm{se}-$ mestre possuem conhecimento avançado em informática (56\%).

Tabela 8 - Nível do conhecimento em Informática dos alunos por termo

\begin{tabular}{lcccc}
\hline Nível Informática & Básico & Intermediário & Avançado & Nenhum \\
\hline $\mathbf{3}^{\circ}$ semestre & $32 \%$ & $42 \%$ & $21 \%$ & $5 \%$ \\
\hline $\mathbf{5}^{\circ}$ semestre & $17 \%$ & $65 \%$ & $17 \%$ & $2 \%$ \\
\hline $7^{\circ}$ semestre & $7 \%$ & $37 \%$ & $56 \%$ & $0 \%$ \\
\hline
\end{tabular}

Fonte: Elaborado pelos autores

Quanto ao conhecimento em outros idiomas, foi escolhido como base para análise o idioma inglês, que é o mais requisitado em programas de estágio e trainees. No que diz respeito à proficiência no idioma inglês, pode-se observar que o período diurno apresenta maior habilidade na língua, já que $48 \%$ responderam ter nível intermediário e 32\% nível avançado. Enquanto no período noturno, 37\% responderam ter nível intermediário e 29,5\% nível avançado (vide Tabela 9).

Esse maior domínio da língua no período diurno pode ser explicado pelo fato de que estes estudantes dispõem de mais tempo para atividades extracurriculares, a exemplo dos cursos de idiomas, já que no período noturno diversos alunos realizam atividades de estágio ou emprego.

Tabela 9 - Nível do conhecimento em língua inglesa dos alunos por período

\begin{tabular}{lcccc}
\hline Nível Inglês & Básico & Intermediário & Avançado & Nenhum \\
\hline Diurno & $19 \%$ & $48,00 \%$ & $32 \%$ & $1 \%$ \\
\hline Noturno & $23,50 \%$ & $37 \%$ & $29,50 \%$ & $10 \%$ \\
\hline
\end{tabular}

Fonte: Elaborado pelos autores 
Com relação a análise do idioma inglês entre os semestre, pode-se notar que há uma sutil evolução do domínio da língua no decorrer do curso, 33\% dos alunos do $3^{\circ}$ termo responderam ter inglês intermediário e $29 \%$ avançado, alunos do $5^{\circ}$ termo responderam ter $44 \%$ inglês intermediário e $29 \%$ avançado e por fim, alunos do $7^{\circ}$ termo responderam ter $50 \%$ inglês intermediário e $35 \%$ nível avançado. Esses dados evidenciam que o $7^{\circ}$ semestre possui maior nível de conhecimento que os demais semestres (vide Tabela 10).

Tabela 10 - Nível do conhecimento em língua inglesa dos alunos por termo

\begin{tabular}{lcccc}
\hline Nível Inglês & Básico & Intermediário & Avançado & Nenhum \\
\hline $\mathbf{3}^{\circ}$ semestre & $29 \%$ & $33 \%$ & $29 \%$ & $9 \%$ \\
\hline $\mathbf{5}^{\circ}$ semestre & $21 \%$ & $44 \%$ & $29 \%$ & $6 \%$ \\
\hline $\mathbf{7}^{\circ}$ semestre & $13 \%$ & $50 \%$ & $35 \%$ & $2 \%$ \\
\hline
\end{tabular}

Fonte: Elaborado pelos autores

Conclui-se há uma evolução gradual da proficiência no idioma inglês, mas ainda um pouco lenta, considerando a importância do conhecimento e da habilidade com estes aspectos demandados atualmente.

Pode-se observar nessa análise que conhecimentos em informática crescem de acordo com a evolução do curso, da participação dos alunos em aulas relacionadas ao tema e a inserção desses no mercado de trabalho, que amplia as habilidades nessa área do conhecimento. Quanto ao domínio de idiomas como o Inglês, observou-se uma lenta evolução no decorrer do curso, mas que ao contrário da informática, é beneficiado pelo tempo disponível dos alunos para realização de cursos de idiomas. Nesse sentido, o noturno apresenta em suma, menor habilidade em inglês em comparação com o diurno.

\section{CONCLUSÕES}

Os dados evidenciaram que as pressões exercidas pelas demandas do mercado de trabalho condicionam a formação dos alunos do curso de Administração da UNESP/Tupã. Isto, conforme exposto, pôde ser evidenciado pelo ajuste do perfil pessoal às demandas de mercado, evidenciado por características interpessoais como flexibilidade e pró-atividade, perfil empreendedor, trabalho em equipe, comunicação, visão sistêmica e capacidade de negociação. 
Além, do desenvolvimento dessas habilidades é prioritário que se consolidem como competências, ou seja, pela capacidade de operação e decisão em procedimentos complexos. Talvez, por isto, ocorra como conseqüência um avanço nos quesitos medidos, em relação ao período em que o aluno está matriculado, o que denota que existe um tempo de maturação das habilidades.

Em complemento, as atividades extracurriculares demonstram a relevância (melhor dizendo, pressão) das exigências do mercado de trabalho. No mesmo sentido, o conhecimento de informática também é um grande atributo complementar à formação do curso de Administração, necessário e demandado pelas empresas, assim como o domínio do Inglês, mostrando a importância destas atividades extracurriculares para a área e provando que o aluno que busca apenas a formação acadêmica pode ser prejudicado no desenvolvimento das competências exigidas pelo mercado de trabalho.

Constata-se então, que o mercado cria pressão sobre o processo de formação dos alunos do curso de Administração da UNESP/Tupã, gerando um processo pró-ativo de complemento da formação. Em pesquisas posteriores, serão buscadas comparações entre os perfis encontrados e o seguimento de mercado em que deseja atuar.

Seria possível pressupor que determinado perfil de graduandos/egressos desejem atuar em segmentos específicos de mercado, mesmo que estejam em períodos ainda iniciais do curso de Administração? Neste mesmo sentido, a pergunta ainda persiste: é o anseio pessoal ou o mercado de trabalho que molda a formação do egresso em Administração?

\section{REFERÊNCIAS}

ALENCAR, Eunice M.; FLEITH, Denise de S. Inventario de praticas docentes que favorecem a criatividade no ensino superior. Psicologia: Reflexão e Crítica, Porto Alegre, v. 17, n. 1, p. 105-110, 2004.

\section{ALVES, Helena M. B. Uma abordagem de marketing à satisfação} do aluno no ensino universitário público: índice, antecedentes e conseqüências. 2003. 285f. Tese (Doutorado em Gestão) - Departamento de Gestão e Economia, Universidade da Beira Interior, Covilhã, Portugal, 2003.

DILLON, William R.; GOLDSTEIN, Matthew. Multivariate Analysis. New York: John Wiley \& Sons, 1984. 
FERREIRA, Armando M. SPSS - Manual de utilização. Escola Superior Agrária de Castelo Branco, 1999.

GARCIA, Mauro N.; DERISIO, Diana P. Fatores de qualidade percebidos pelos discentes do curso de administração de IES municipais do Grande ABC. Revista de Administração da UNIMEP, Piracicaba, v. 5, n. 2, p. 1-27, maio/ago. 2007.

GIL, Antonio C. Métodos e técnicas de pesquisa social. 6. ed. São Paulo: Atlas, 2009.

GONÇALVES FILHO, Cid; GUERRA, Renata S.; MOURA, Alexandre. Mensuração de satisfação, qualidade, lealdade com a instituição, valor e expectativa em instituições de ensino superior: um estudo do modelo ACSI através de equações estruturais. In: ENCONTRO DA ASSOCIAÇÃO NACIONAL DOS PROGRAMAS DE PÓS-GRADUAÇÃO EM ADMINISTRAÇÃO, 27., 2003, Atibaia, SP. Anais... Rio de Janeiro: ANPAD, 2003.

HAIR JR., Joseph F.; ANDERSON, Rolph E.; TATHAM, Ronald L. Análise multivariada de dados. 5. ed. Porto Alegre : Bookman, 2005.

HENNIG-THURAU, Thorsten; LANGER, Markus F.; HANSEN, Ursula. Modeling and managing student loyalty: an approach based on the concept of relationship quality. Journal of Service Research, Thousand Oaks, v. 3, n. 4, p. 331-344, may. 2001.

KAREMERA, David; REUBEN, Lucy J.; SILLAH, Marion R. The effects of academic environment and background characteristics on student satisfaction and performance: the case of South Carolina State university's school of business. College Student Journal, Chula Vista (CA), v. 37, n. 2, p. 298-308, 2003.

KANO, N., Attradive. Quality and Must-be Quality. Society for Quality Control, Tokyo, p.39-48, abril, 1984.

LIN, Chieh-Peng; TSAI, Yuan H. Modeling educational quality and student loyalty: a quantitative approach based on the theory of information cascades. Quality \& Quantity, Itália, v. 42, n. 3, p. 397-415, 2006.

MALHOTRA, Naresh K. Pesquisa de marketing: uma orientação aplicada. 3. ed. Porto Alegre: Bookman, 2001. 
MARCHESAN, Teresinha M.; SOUZA, Adriano M.; MENEZES, Rui. Avaliação do Processo de ensino: uma Abordagem multivariada. Produção, São Paulo, v. 21, n. 2, abr./jun. 2011.

MARKS, Ronald B. Determinants of student evaluations of global measures of instructor and course value. Journal of Marketing Education, Thousand Oaks (CA), v. 22, n. 2, p. 108-119, aug. 2000.

MAROCO, João. Análise estatística. 2. ed. Lisboa : Edições Silabo, 2003.

MARZO-NAVARRO, Mercedes; PEDRAJA-IGLESIAS, Marta; RIVERATORRES, M. Pilar. Measuring customer satisfaction in summer courses. Quality Assurance in Education, Bradford (UK), v. 13, n. 1, p. 56-65, 2005.

MELLO, Sérgio C. B. de; DUTRA, Hérrisson F. de O.; OLIVEIRA, Patrícia A. da S. Avaliando a qualidade de serviço educacional numa IES: o impacto da qualidade percebida na apreciação do aluno de graduação. Organizações \& Sociedade, Salvador, v. 8, n. 21, p. 125-137, maio./ago. 2001.

REINERT, José N.; REINERT, Clio. Estudante não é cliente: é parceiro. In: ENCONTRO DA ASSOCIAÇÃO NACIONAL DE PÓS-GRADUAÇÃO E PESQUISA EM ADMINISTRAÇÃO, 29., 2005, Brasília, DF. Anais... Rio de Janeiro: ANPAD, 2005.

RODIE, Amy R.; KLEINE, Susan S. Customer participation in services production and delivery. In: SWARTZ, Teresa A; IACOBUCCI, Dawn (Eds.). Handbook of service marketing and management, Sage: Thousand, p. 111-125, 2000.

SOUZA, Saulo A. de; REINERT, José N. Avaliação de um curso de ensino superior através da satisfação/insatisfação discente. Avaliação, Campinas; Sorocaba, v. 15, n. 1, p. 159-176, mar. 2010.

WALTER, Silvana A. Antecedentes da satisfação e da lealdade de alunos de uma instituição de ensino superior. 2006. 167f. Dissertação (Mestrado em Administração) - Programa de Pós-Graduação em Administração, Universidade Regional de Blumenau, Blumenau, 2006.

WALTER, Silvana A.; TONTINI, Gérson; DOMINGUES, M. J. C. S. Análise da Satisfação do Aluno para Melhoria de um Curso de Administração. Revista FACES, Belo Horizonte, v. 6, p. 52-70, 2006. 